Survey questions included religious values, practices, behaviors, civic engagement, and religious commitment.

\section{Measuring Religious Experience: An Item Response Theory Analysis of Religious Experiences}

Joe Chelladurai

\begin{abstract}
Apart from its wide usage in educational testing and scale development, Item Response Theory analysis has not been used as much in the study of religion and spirituality. Taking advantage of the psychometric abilities of IRT, in this paper, I examine a measure of religious experiences. Particularly, I employ the Rasch model along with two parametric and three parametric logistic models for dichotomous outcomes. In general, findings from the analysis suggest low discriminatory and low difficulty parameters on the items except for one item which measured change as a result of religious experience.
\end{abstract}

Keywords: item response theory, dichotomous variables, religious experiences, scale development

The field of psychology of Religion and Spirituality is interested in examining the human connection with the sacred. Religious experiences are one of the most indicative aspects of religiosity. Although religious experiences may not be fully examined quantitatively, a social survey of the phenomenon may be of interest to inform further research. Moreover, using such data in conjunction with advances in measurement theory can help to develop and refine constructs of religion and spirituality. In this regard, I examine a measure of religious experience in a nationally representative survey using Item Response Theory models.

Item Response Theory investigates the latent traits of respondents and uses the test items as indicators or predictors of measured responses. This allows researchers to examine respondents and their responses in the same statistical model. The basis of IRT is the assumption that people respond with differing abilities. Depending on the measure, there may be more than one type of ability or latent trait. Although commonly used for testing, IRT models are valuable to build models to explain ways respondents answer survey questions and offer possibilities to examine differences in abilities or traits.

\section{Participants}

\section{Method}

Participants for this study are from the 2005 Baylor Religion Study. The survey was self-administered and resulted with 1,721 participants from the United States. The final data was weighted to be nationally representative.

\section{Measures}

Religious Experience Scale. The four-item religious experience scale for this study was taken from Wave I of the Baylor Religion Survey (2005). The original scale had nine experiences. Items indicating personal experiences with religion were selected. Participants reported on the following items:

- I heard the voice of God speaking to me

- I had a dream of religious significance

- $\quad$ I changed profoundly as the result of a religious experience

- I had a religious conversion experience

\section{Analysis Plan}

I examined four different models of Item Response Theory: Rasch model with constraints (Model 1), Rasch model without constraints (Model 2), Two-Parameter Logistic Model (Model 3), and Three-Parameter Logistic Model (Model 4).

\section{Results}

\section{Rasch Model with Constraints (Model 1)}

A Rasch model with constraints was identified. The discrimination value was set at 1 .

\begin{tabular}{llll}
\hline & Difficulty & Discrimination & $P(x=1 \mid z=0)$ \\
\hline Item 1 & 2.13 & 1 & .05 \\
Item 2 & 1.45 & 1 & .11 \\
Item 3 & 1.06 & 1 & .18 \\
Item 4 & 1.21 & 1 & .15 \\
\hline
\end{tabular}

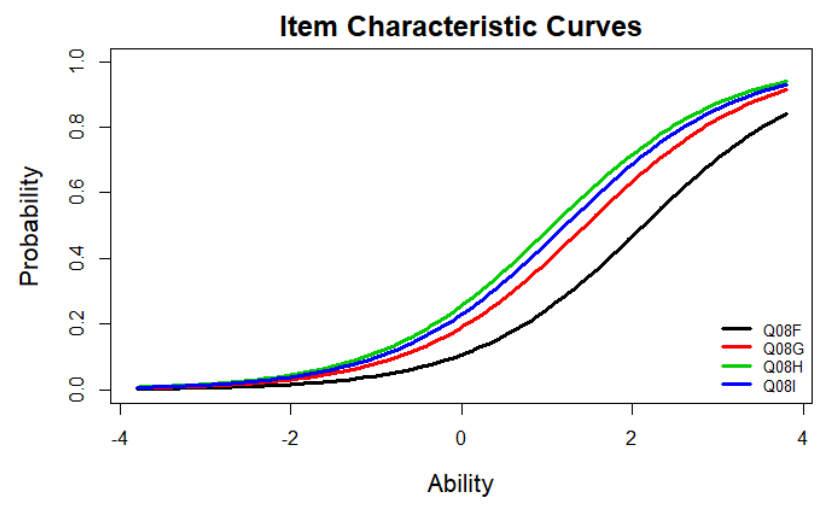

Rasch Model with Unconstrained Discrimination (Model 2)

A Rasch model with constant discriminatory values was identified. The discrimination value from the model was 2.17

\begin{tabular}{llll}
\hline & Difficulty & Discrimination & $\mathrm{P}(\mathrm{x}=1 \mid \mathrm{z}=0)$ \\
\hline Item 1 & 2.13 & 2.17 & .05 \\
Item 2 & 1.45 & 2.17 & .11
\end{tabular}




\begin{tabular}{llll} 
Item 3 & 1.06 & 2.17 & .18 \\
Item 4 & 1.21 & 2.17 & .15 \\
\hline
\end{tabular}

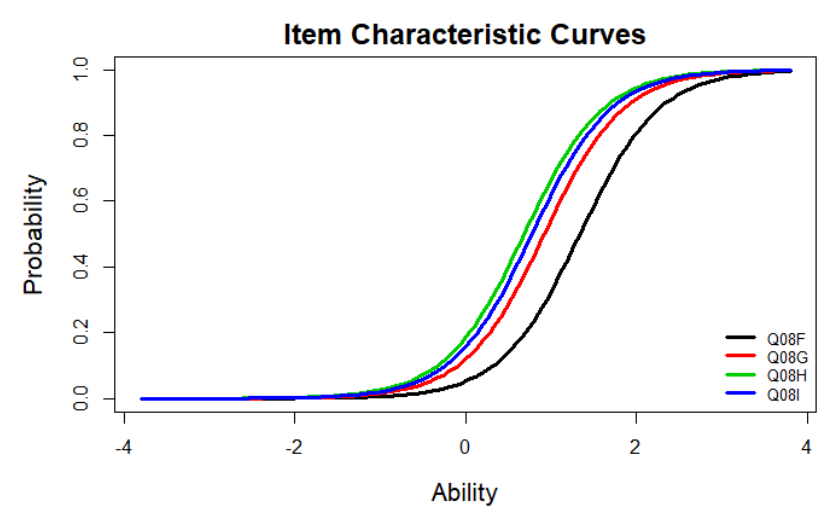

Comparison between model 1 and model 2 . The constrained and unconstrained model with constant discriminatory value were compared. The difference in model fit indices was significant $(p<.001)$. Results are presented in the following table.

\begin{tabular}{lllllll}
\hline Model & AIC & BIC & Log.lik & LRT & df & $p$ \\
\hline Model 1 & 6486.11 & 6507.91 & -3239.05 & & & \\
Model 2 & 6222.88 & 6252.13 & -3107.44 & 263.23 & 1 & .001 \\
\hline
\end{tabular}

\section{Two-Parameter Logistic Model (Model 3)}

The two-parameter logistic model allows to vary the discrimination parameter. Model fit indices denoted whether the model fit the data better than the Rasch model. From the results, we note that discrimination values differ for each item, with item 3 having the highest discrimination value. This suggests that item 3 may discriminate well between those who have religious experiences versus those who have not.

\begin{tabular}{llll}
\hline & Difficulty & Discrimination & $P(x=1 \mid z=0)$ \\
\hline Item 1 & 1.46 & 1.76 & .07 \\
Item 2 & 1.27 & 1.16 & .18 \\
Item 3 & 0.57 & 6.00 & .03 \\
Item 4 & 0.71 & 2.80 & .11 \\
\hline
\end{tabular}

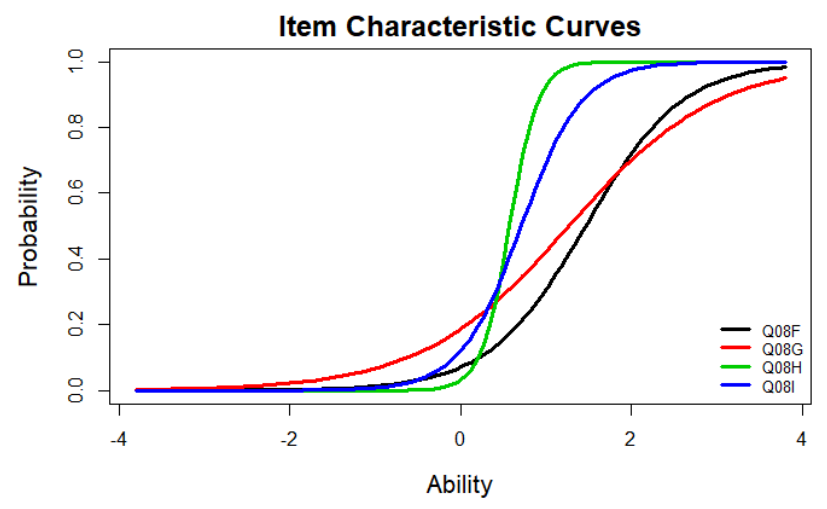

Comparison between model 2 and model 3. The unconstrained model with constant discriminatory value and the model with freely estimated discrimination values were compared. The difference in model fit indices was significant $(p<.001)$. Results are presented in the following table.

\begin{tabular}{lllllll}
\hline Model & AIC & BIC & Log.lik & LRT & df & $p$ \\
\hline Model 2 & 6224.88 & 6252.13 & -3107.44 & & & \\
Model 3 & 6125.93 & 6169.54 & -3054.97 & 104.94 & 3 & .001 \\
\hline
\end{tabular}

\section{Three-Parameter Logistic Model (Model 4)}

A three-parameter logistic model is used to examine whether there was guessing in the model.

\begin{tabular}{lllll}
\hline & Guessing & Difficulty & Discrimination & $P(x=1 \mid z=0)$ \\
\hline Item 1 & 3.71 & 1.36 & 3.12 & .04 \\
Item 2 & 1.26 & 1.33 & 3.12 & .14 \\
Item 3 & 2.70 & 0.61 & 3.12 & .12 \\
Item 4 & 3.60 & 0.70 & 3.12 & .10 \\
\hline
\end{tabular}

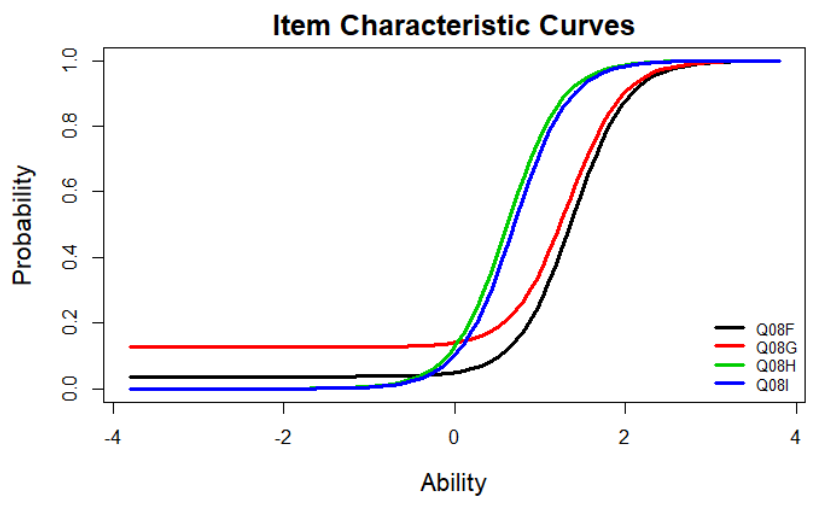

Comparison between model 3 and model 4 . The three-parameter model did not fit better than Model 3. This suggests that guessing was not an issue in the data.

\begin{tabular}{lllllll}
\hline Model & AIC & BIC & Log.lik & LRT & df & $p$ \\
\hline Model 3 & 6125.93 & 6169.54 & -3054.97 & & & \\
Model 4 & 6169.78 & 6218.84 & -3075.89 & -41.85 & 1 & 1 \\
\hline
\end{tabular}

\section{Discussion}

Findings from the item response theory models suggest that items have varying discriminatory and difficulty parameters. The models were valuable as we were able to extract which items were more indicative of participants who reported having religious experiences compared to participants who did not. 
Particularly, the item "I changed profoundly as the result of a religious experience" had a high discriminatory value. This item provides a stronger indicator on religious experience. However, based on the purpose of the scale, this item may be removed as it measures an outcome of religious experience rather than indications of religious experience as other items demonstrate. The models also provided insights based on whether guessing was involved. As results of the guessing model were non-significant, this analysis establishes stronger data quality.

Item response theory can be helpful to examine dichotomous and polytomous outcomes. Future research can examine Likert-type responses as well as examine multidimensionality of religious constructs. Examining constructs of religion and spirituality will enable better quality and refined measurement of a what can be a complex and dynamic field of study. The plurality of definitions of religion and spirituality may add a unique challenge. It is therefore vital that researchers examine the underlying properties of measurement constructs prior to examining diverse populations and thereby advance the study of religion and spirituality.

\section{References}

Baylor University (2005). The Baylor Religion Survey. Waco, TX: Baylor Institute for Studies of Religion

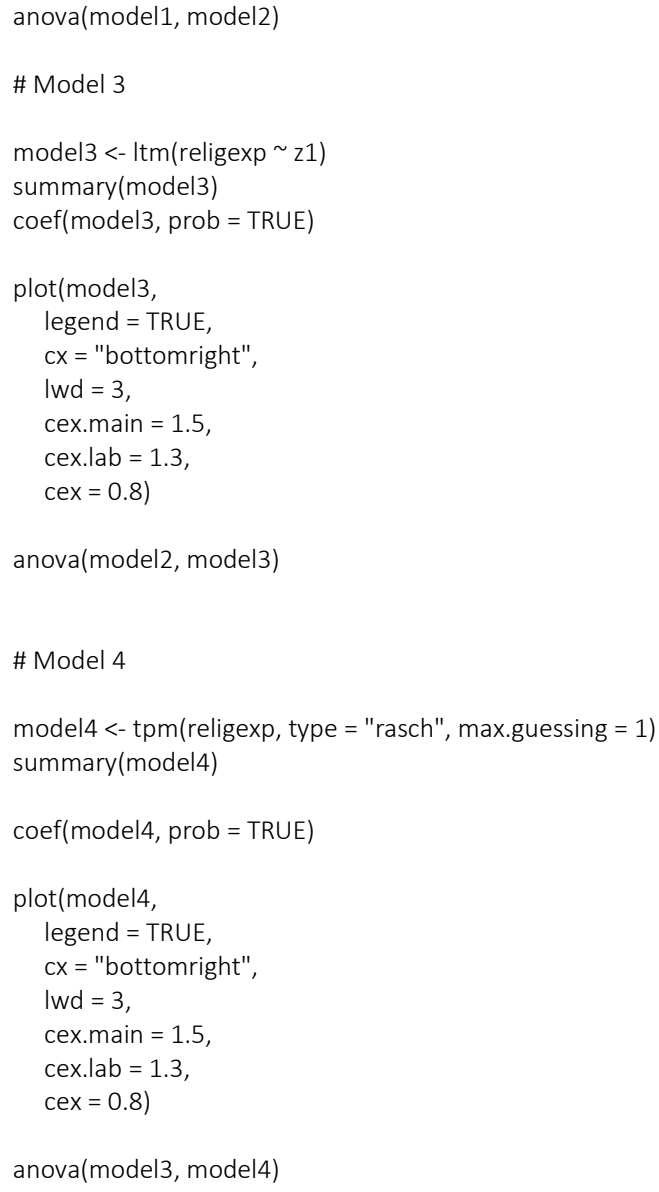

\section{Appendix}

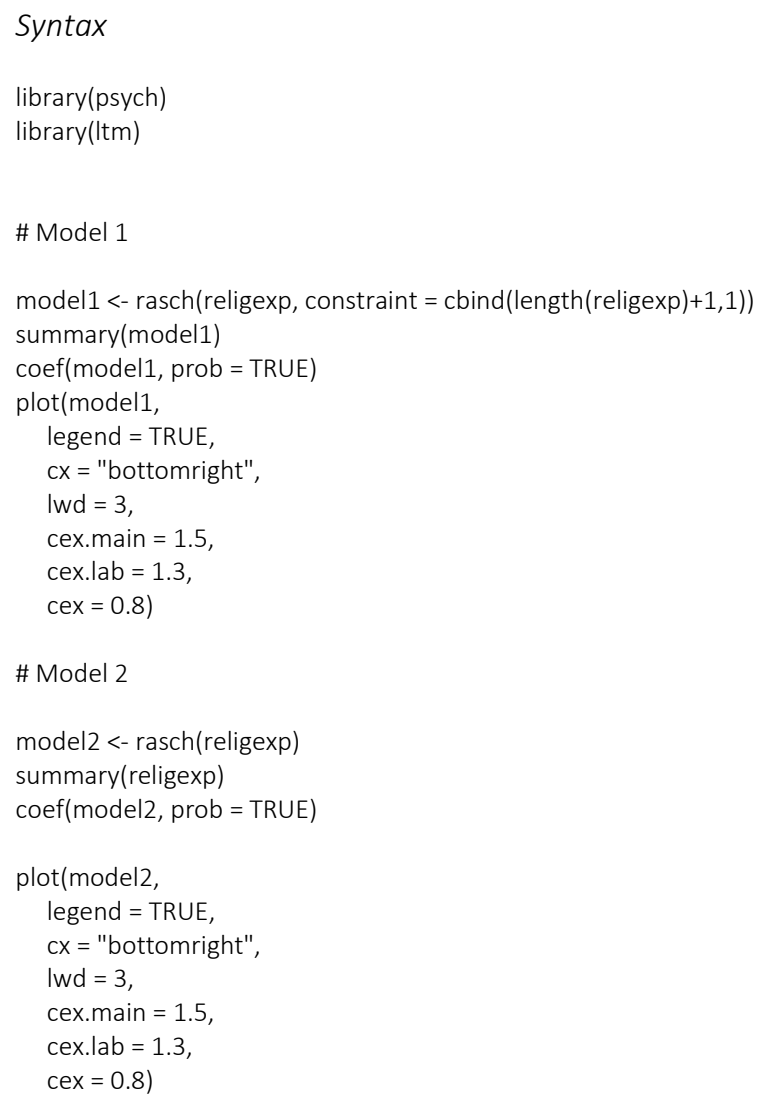

